\title{
An Audit of Maternal Mortality at a Tertiary Care Hospital
}

\author{
Shazia Naseeb, Piranka Kumari, Iqra Jam, Haleema Yasmin \\ - - - - - - - - - - - - - - - - - - - - - - - - - - -
}

ABSTRACT:

Objective: To find causes of maternal deaths and to calculate maternal mortality ratio at tertiary care hospital Karachi.

Study Design and setting: An observational study was conducted from1st January 2019 to $31^{\text {st }}$ December 2020 at the Department of Obstetrics \& Gynecology Unit 1, JPMC Karachi.

Methodology: Patients were selected according to inclusion criteria after ethical approval through non probability consecutive sampling technique. Details of patients were obtained from files and record registers. Their demographic feature like age, parity, gestational age, booking status and presence or absence of medical disorders, their status of delivery and direct and indirect reasons of maternal deaths were noted and their frequency and percentages were calculated. Brought dead patients and those who died accidently were excluded from the study.

Results: During the period of two years the total numbers of deaths certified in the department were 90 . Total number of child birth and live births were 19084 and 17892 respectively. The maternal mortality ratio was estimated as 503.01 per 100,000 live births. Most of the patients 74(82.3\%) were un booked. Direct Causes were about 67(74.5\%). Haemorrhage was found to be most common reason of maternal deaths in about 21(23.3\%). Eclampsia among18(20\%) deaths. Anemia, cardiac disease, hepatic failure were the indirect causes of maternal deaths responsible for $23(25.5 \%)$ of maternal deaths.

Conclusion: Maternal Death rate is persistently elevated in JPMC, being tertiary care hospital mostly due to serious and referred complicated cases. Haemorrhage and eclampsia are still major killers of mothers as before.

Keywords: Eclampsia, Haemorrhage, Maternal Mortality, Safe Motherhood.

- - - - - - - - - - - - - - - - - - - - - - - - -

Article:

Naseeb S, Kumari P, Jam I, Yasmin H. An Audit of Maternal Mortality at a Tertiary Care Hospital. J Bahria Uni Med Dental Coll. 2021; 11(4):153-157. DOI: https://doi.org/10.51985/JBUMDC2021026

This is an Open Access article distributed under the terms of the Creative Commons Attribution Non Commercial License (http:// creativecommons/org/licences/by-nc/4.0) which permits unrestricted non commercial use, distribution and reproduction in any medium, provided the original work is properly cited.

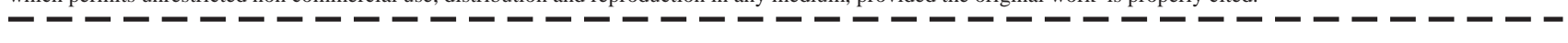

\section{INTRODUCTION:}

Maternal death is defined as death of women while pregnant or within 42 days of termination of pregnancy irrespective from any causes related to or aggravated by pregnancy or its management, but not from accidental causes. ${ }^{1}$ Maternal deaths are divided into two categories: Direct obstetric deaths and indirect obstetric deaths. The latter are deaths for which there was a preexisting disease that was aggravated by the pregnancy. According to United Nations Population Fund (UNFPA) 2017 in every two minutes one women dies. ${ }^{2}$ Maternal mortality is unacceptably high, about 295000

I Shazia Naseeb
Associate Professor, Department of Obstetrics and Gynecology |
Jinnah Post Graduate and Medical Center, Karachi
Email: snkhan1975@ yahoo.com
Piranka Kumari
Postgraduate Student, Department of Obstetrics and Gynecology I
I Jinnah Post Graduate and Medical Center, Karachi
I Iqra Jam
I Postgraduate Student, Department of Obstetrics and Gynecology
I Jinnah Post Graduate and Medical Center, Karachi
I Haleema Yasmeen
I Professor, Department of Obstetrics and Gynecology
I Innah Post Graduate and Medical Center, Karachi
I Received: 06-May-2021
I Accepted: 14-Sep-2021 women died during and following pregnancy and childbirth in 2017. The vast majority of these deaths (94\%) occurred in low-resource settings, and most could have been prevented. ${ }^{3}$ Having the population of approximately 204.6 million people, Pakistan is the sixth most populous country in the world. In Pakistan, the maternal mortality rate (MMR) was 140 per 100,000 live births in $2017 .{ }^{4}$ Although there have been significant improvements in the country's healthcare system, Pakistan still faces many challenges in relation to its high population growth, infant and maternal mortality, and many infectious and non-infectious diseases. ${ }^{5}$

There is great variation in MMR of developing and developed countries worldwide. Many factors play a role in contribution of high MMR in developing countries like religious, social and cultural beliefs, poor socioeconomic condition, inappropriate diet, delay in seeking medical advice, delay in approaching medical facility and delay in management, presence of co- morbidities, infections, high fertility rate and low literacy rate and virtually all are avoidable.

UNFPA estimated that 303,000 women died of pregnancy or childbirth related causes in 2015 . $^{2}$ The causes range from to ${ }^{6}$ for which there are highly effective interventions. As women have gained access to and skilled with backup emergency obstetric care, the global maternal mortality ratio has fallen from 385 maternal deaths per 100,000 live births 
in 1990 to 2016 deaths per 100,000 live births in 2015, and many countries halved their maternal death rates in the last 10 years. ${ }^{2}$

According to a study which covered the period from 1990 to 2013 , the most common causes are (15\%), complications from unsafe $(15 \%),(10 \%),(8 \%)$, and $(6 \%) .{ }^{6}$ Other causes include $(3 \%)$ and pre-existing conditions (28\%). ${ }^{7}$ Maternal mortality caused by severe bleeding and infections are mostly after childbirth. Indirect causes are malaria, anemia, ${ }^{8}$ HIV/AIDS and cardiovascular disease may complicate pregnancy or be aggravated by it. ${ }^{9}$ Risk factors associated with increased maternal death include the age of the mother, obesity before becoming pregnant, other pre-existing chronic medical conditions, and cesarean delivery. ${ }^{10,11}$

Maternal mortality is an outcome measure of health and development system ${ }^{1}$. Repeated Audit on maternal deaths are necessary in order to check weaknesses and improvement in health system in order to save mothers. Hence; the present study was carried out to find out reason of maternal deaths and to calculate maternal mortality ratio at JPMC, tertiary care Hospital.

\section{METHODOLOGY:}

This study was carried out in department of Obstetrics and Gynecology JPMC from Jan 2019- Dec.2020 after ethical approval from institutional review board. This was an observational analytic study. The study was conducted with approval from institutional review board of JPMC letter no.F.2-81/2021GENL/6275/JPMC). Relevant data of number of obstetric admissions, number of childbirth, number of live births, number of maternal deaths and their characteristics have been obtained from the records of the department. Patients were selected through non probability consecutive sampling technique, meeting inclusion criteria in which all pregnant patients of any age, any parity at any gestational age, irrespective of their booking status, with or without medical disorders, disregarding the delivery status, died due to direct or indirect reason of maternal deaths. Pregnant brought dead patients and those who died accidently were excluded from the study. The reasons of mortality were categorized as in chapter 15 of the tenth revision of the international statistical classification of diseases and related health problems (ICD10) 4. More than one factor may have been the cause of death but the seemingly dominating factor was marked as the cause of death. This was based on clinical judgment, as no autopsy was performed in any case. Data is analyzed on SPSS Version 23. The qualitative variables such as maternal deaths, booked or un-booked cases, age, parity, delivery status and causes of deaths presented by their frequencies along with percentages and $95 \%$ confidence intervals. The effect modifier such as age and parity were grouped.

\section{RESULTS:}

During two years period total number of deaths certified in the department were 90, during the same year the number of childbirth and number of live births were 19084 and 17892 respectively. Maternal mortality Ratio was 503.01 per 100,000 live births.

The demographic profile of all maternal deaths is given in (Table 1). Direct causes were responsible for $74.4 \%$ of deaths. Haemorrhage was the main direct cause and was seen in $21(23.3 \%)$ deaths, nearly $71.4 \%$ of the patients died of post-partum haemorrhage. Eclampsia was responsible for $18(20 \%)$ deaths. It was the leading cause among all women having their first baby. Total seven $(7.8 \%)$ patients died as a result of complications of unsafe abortion. Total twenty-three $(25.5 \%)$ of the patients died as a result of severe anemia, cardiac disease and hepatic failure. (Table 2).

\section{DISCUSSION:}

MMR in JPMC in the last three decades from 1960-1969 was 889, 1981-1990 was 710 and 1991- 1999 was 883 however the current study shows a slight decrease in MMR. ${ }^{12,13}$ In our study maternal mortality ratio is 503.01 per 100,000 live births. One study which was conducted at Lahore reported MMR of 451/100,000 live birth. ${ }^{14}$ Almost similar result was obtained from the study conducted at Peshawar and reveals MMR of 431/100,000 live birth. ${ }^{15}$ Maternal Deaths due to pregnancy related problem are highest and same in JPMC when we compared with other teaching institutes of Pakistan and other developing countries. ${ }^{14,15,16}$ Direct causes of maternal mortality are still the most frequent causes in this institution, Haemorrhage alone is responsible for 21(23.3\%) of maternal deaths, during the study period; this is much lower than the other studies reported from other tertiary care centers in Pakistan. ${ }^{14,15,17}$ This is generally due to delay of referral of serious and complicated cases to the hospital. and they have usually delivered either at their home or at some small private maternity clinics. These women came in deteriorated condition, in irreversible hypovolemic shock and died despite availability of specialist doctors and blood transfusion facilities. Eclampsia was found to be $2^{\text {nd }}$ commonest and leading cause of maternal death in our study similar finding noted from other studies. ${ }^{14,}{ }^{15,18}$ In this study $13(14.4 \%)$ of the patients had ruptured uterus due to previous scar, CPD and malpresentation. It is also comparable with one study reported from Nigeria where 3(11.8\%) maternal deaths from ruptured uterus. ${ }^{19}$ while other study from Pakistan shows high rate $(34 \%)$ of maternal deaths from ruptured uterus. ${ }^{20}$

Unsafe abortion were accounted for 7(7.8\%) of maternal deaths in our study, These were due to septic induced abortions. This is much lower than reported from Karim $\mathrm{K} .{ }^{21}$ where it was responsible for $10-12 \%$ of maternal deaths while in Sudan the abortion was seen in $3.9 \%$ of maternal deaths. ${ }^{22}$, This reconfirms the fact that even in a metropolitan city like Karachi where access to family planning clinics is 
Table 1: Demographic Profile of Maternal Deaths

\begin{tabular}{|c|c|c|c|}
\hline & Maternal Deaths & $95 \% \mathrm{CI}^{*}$ & \\
\hline No. of Maternal Deaths & $\begin{array}{c}90 \\
(506 \text { Per 100,000) }\end{array}$ & $\begin{array}{c}72-109 \\
(410-618) \text { Per100,000 }\end{array}$ & \\
\hline Booked & $16(17.7 \%)$ & $10.9-26.7$ & \\
\hline Un-booked & $74(82.3 \%)$ & $73.3-89.1$ & \\
\hline Age in years & & & Cumulative (\%) \\
\hline $15-20$ & $4(4.4 \%)$ & $1.4-10.4$ & $4.4 \%$ \\
\hline $21-30$ & $58(64.4 \%)$ & $54.2-73.8$ & $68.9 \%$ \\
\hline $31-40$ & $26(28.9 \%)$ & $20.2-38.8$ & $97.8 \%$ \\
\hline$>40$ & $2(2.2 \%)$ & $1.4-10.4$ & 100.) $\%$ \\
\hline PARITY & & & Cumulative (\%) \\
\hline $0+0$ & $8(8.9 \%)$ & $4.2-16.2$ & $8.9 \%$ \\
\hline $1-4$ & $62(68.9 \%)$ & $58.8-77.8$ & $77.8 \%$ \\
\hline $5 \&$ more & $20(22.2 \%)$ & $14.5-31.7$ & $100.0 \%$ \\
\hline \multicolumn{4}{|l|}{ Delivery Status } \\
\hline Abortion & $4(4.4 \%)$ & $1.4-10.4$ & \\
\hline Un-delivered & $13(14.4 \%)$ & $8.3-22.1$ & \\
\hline Delivered & $73(81.2 \%)$ & $72.0-88.2$ & \\
\hline
\end{tabular}

Table 2: Cause of deaths

\begin{tabular}{|l|c|c|}
\hline \multicolumn{2}{|c|}{ Causes of death } & 95\% \\
n $=90$ & Confidence Interval \\
\hline DIRECT & $\mathbf{6 7}(\mathbf{7 4 . 4} \%)$ & $\mathbf{6 4 . 7 - 8 2 . 6}$ \\
Haemorrhage & $\mathbf{2 1}(\mathbf{2 3 . 3 \%})$ & $\mathbf{1 5 . 5}-\mathbf{3 2 . 1}$ \\
Postpartum Haemorrhage & $15(16.7 \%)$ & $\mathbf{1 0 . 0}-\mathbf{2 5 . 4}$ \\
Placenta accreta & $7(7.8 \%)$ & $\mathbf{3 . 5}-\mathbf{1 4 . 8}$ \\
Atony of uterus & $5(5.6 \%)$ & $\mathbf{2 . 1}-\mathbf{1 1 . 9}$ \\
Trauma (cervical \& perineal tears) & $3(3.3 \%)$ & $\mathbf{0 . 9}-\mathbf{8 . 8}$ \\
\hline Antepartum hemorrhage & $6(6.7 \%)$ & $2.7-13.6$ \\
Abruptio & $4(4.4 \%)$ & $1.4-10.4$ \\
Placenta previa & $2(2.2 \%)$ & $0.4-7.1$ \\
\hline Eclampsia & $\mathbf{1 8}(\mathbf{2 0} \%)$ & $\mathbf{1 2 . 7}-\mathbf{2 9 . 2}$ \\
Antepartum & $16(17.8 \%)$ & $\mathbf{1 0 . 9}-\mathbf{2 6 . 7}$ \\
Postpartum & $2(2.2 \%)$ & $\mathbf{0 . 4}-\mathbf{7 . 1}$ \\
\hline Ruptured uterus & $\mathbf{1 3 ( 1 4 . 4 \% )}$ & $\mathbf{8 . 3 - 2 2 . 9}$ \\
Previous scar & $7(7.8 \%)$ & $\mathbf{3 . 5}-\mathbf{1 4 . 8}$ \\
CPD & $5(5.5 \%)$ & $\mathbf{2 . 1}-\mathbf{1 1 . 9}$ \\
Malpresentation & $1(1.1 \%)$ & $\mathbf{0 . 0 6}-\mathbf{5 . 4}$ \\
\hline Sepsis & $\mathbf{7 ( 7 . 8 \% )}$ & $\mathbf{3 . 5}-\mathbf{1 4 . 8}$ \\
\hline Abortion & $\mathbf{7 ( 7 . 8 \% )}$ & $\mathbf{3 . 5}-\mathbf{1 4 . 8}$ \\
\hline Embolism & $\mathbf{1 ( 1 . 1 \% )}$ & $\mathbf{0 . 0 6}-\mathbf{5 . 4}$ \\
\hline INDIRECT CAUSES & $\mathbf{2 3 ( 2 5 . 5 \% )}$ & $\mathbf{1 7 . 4 - 3 5 . 3}$ \\
Cardiac disease & $11(12.2 \%)$ & $\mathbf{6 . 6}-\mathbf{2 0 . 2 5}$ \\
Anemia & $8(8.9 \%)$ & $\mathbf{4 . 2}-\mathbf{1 6 . 2}$ \\
Hepatic failure & $4(4.4 \%)$ & $\mathbf{1 . 4}-\mathbf{1 0 . 4}$ \\
\hline
\end{tabular}


not an issue, women do not use contraception but opt for abortion to terminate an unwanted and unplanned pregnancy, usually under unsafe conditions. ${ }^{7,23}$ Similar results were also shown in other studies from outside country. ${ }^{23,24}$

In the current study cardiac diseases was the main indirect cause of maternal death. This is not comparable with other national and international studies which showed anemia was the leading indirect cause of maternal deaths. ${ }^{14,22}$ Most of the cardiac disease patients were nonbooked and received in moribund condition from the other hospitals and periphery. Deaths from severe anemia are still high, as shown in our previous study and studies from other teaching institutions of this country, ${ }^{14}$, due to high prevalence of anemia in the population especially in pregnant women. We found same results from the national or international studies. ${ }^{24,25}$ Another major thing is booking status, Majority of women in our study were non booked that is 74( 82.3). Most of the women in the country and neighboring countries do not realize the significance of antenatal care and therefore do not seek advice and remain untreated. ${ }^{15,26,27}$

There are some limitations of this study. First, this is a secondary data analysis and data were extracted from patient's file which is not collected for this study therefore there could be missing variables. Second, the low number of maternal deaths were reported due to precautions taken by the government to prevent the COVID-19 infection and therefore, chances of underreporting cannot be ruled out. Third, in COVID-19 era, few deliveries occured that can lead to high maternal mortality because of small denominator.

\section{CONCLUSION:}

Maternal mortality rate is higher at JPMC, being tertiary care hospital due to referrals of very serious and complicated cases from all over the city as well as from interior of Sindh. There is a need to pay attention to peripheral hospitals by periodic teaching training through workshops for midwifes, doctors and general practitioners and by creating awareness programs through media for patients. Moreover, emphasis on importance of antenatal care for early identification of risk factors, prompt referral of complicated cases with quick involvement of skill persons by taking multidisciplinary approach in case of medical co- morbidities is needed which can save lives of mothers

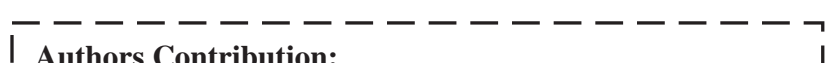

Authors Contribution:

I Shazia Naseeb: Conception and design of study, writeup, and | data analysis.

Piranka Kumari: Data collection

I Iqra Jam: Data collection,

I Haleema Yasmeen: Supervising the work and proof reading |

ㄴ - - - - - - - - - - - - - - REFERENCES:

1. "Health statistics and information systems: Maternal mortality ratio (per 100000 live births)". World Health Organization. Retrieved June 17, 2016
2. "Maternal health.”United Nations Population Fund. Retrieved 2017.01-29.

3. Trends in maternal mortality:2000to 2017:estimates by WHO, UNICF, UNFPA, World Bank Group and the united Nations population Division, Geneva: word Health Organiation; 2019 ISBN: 978-92-4-151648-8

4. World Bank. Maternal mortality ratio (modeled estimate, per 100,000 live births)_Pakistan. https://data.worldbank.org /indicator/SH.STA.MMRT?locations=PK.

5. Kumar S, Bano S comparisons a health care and analysis of health care system: Pakistan Versus Bangladesh, J Hosp ME manage.2017; 3:1. DOI: https://doi.org/10.4172/24719781.100020

6. Abubakar II, Tillmann T, Banerjee A. Global, regional, and national age-sex specific all-cause and cause-specific mortality for 240 causes of death, 1990-2013: a systematic analysis for the Global Burden of Disease Study 2013. Lancet. 2015 Jan 10; 385(9963):117-71. DOI: https://doi.org/10.1016/S01406736(14)61682-2

7. "Maternal mortality: Fact sheet N0 348" World Health Organization. WHO retrieved 20 June 2014.

8. White NJ. Anaemia and malaria. Malaria journal. 2018 Dec; 17(1):1-7. DOI: https://doi.org/10.1186/s12936-018-2509-9

9. Nair M, Nelson-Piercy C, Knight M. Indirect maternal deaths: UK and global perspectives. Obstetric medicine. 2017 Mar; 10(1):10-5. DOI: https://doi.org/10.1177/1753495X16689444

10. Molina RL, Pace LE. A renewed focus on maternal health in the United States. The New England journal of medicine. 2017 Nov 2; 377(18):1705-7. DOI: https://doi.org/ 10.1056 /NEJMp1709473.

11. Kilpatrick SK, Ecker JL, American College of Obstetricians and Gynecologists. Severe maternal morbidity: screening and review. American journal of obstetrics and gynecology. 2016 Sep 1; 215(3):B17-22. DOI: https://doi.org/10.1016/j.ajog. 2016.07.050.

12. Jafarey SN. Maternal mortality in Pakistan--compilation of available data. J Pak Med Assoc. 2002; 52(12):539-44.

13. Jafarey SN. Review of maternal mortality over 10 year's period at Jinnah Postgraduate Medical Centre, Karachi. JPMA $1972 ;$; 3$): 71-76$.

14. Humayun S. Maternal mortality in Pakistan: An attention seeking problem. Journal of the Society of Obstetrics and Gynaecologists of Pakistan. 2017 Jun 13; 7(1):22-7. ISSN NO.Online: 2307-7115

15. Rafiq S, Syed W, Ghaffar SF. Trends and causes of maternal mortality in a tertiary care hospital over five years: 20132017. Pakistan journal of medical sciences. 2019 Jul; 35(4):1128. DOI: https://doi.org/10.12669/pjms.35.4.1091

16. Gupta SD, Khanna A, Gupta R, Sharma NK, Sharma ND. Maternal mortality ratio and predictors of maternal deaths in selected desert districts in Rajasthan: a community-based survey and case control study. Women's Health Issues. 2010 Jan 1; 20(1):80-5.

17. Legesse T, Abdulahi M, Dirar A. Trends and causes of maternal mortality in Jimma University specialized hospital, Southwest Ethiopia: a matched case-control study. International journal of women's health. 2017; 9: 307. DOI: https://doi.org/ 10.2147 /IJWH.S123455 
18. Khan T, Laul P, Laul A, Ramzan M. Prognostic factors of maternal near miss events and maternal deaths in a tertiary healthcare facility in India. International Journal of Gynecology \& Obstetrics. 2017 Aug;138(2):171-6. DOI: https://doi.org/ 10.1002 /ijgo. 12208

19. Awoyesuku PA, MacPepple DA, Altraide BO. Magnitude, Trends and Causes of Maternal Mortality: A 7-year Review at a Tertiary Hospital in Rivers State, Nigeria. Journal of Advances in Medicine and Medical Research. 2020 Feb 15:103-9. DOI: https://doi.org/ 10.9734/ jammr /2020 /v32i130357

20. Noor S, Wahid N, Ali S, Ali S. Maternal Mortality: A 5-year analysis at a District Headquarter Hospital in Pakistan. J Ayub Med Coll Abbottabad. 2019;32(Suppl 1):655-8.

21. Karim K, Ahmed AA. Abortion: A Leading Cause of Maternal Mortality in Pakistan. i-Manager's Journal on Nursing. 2017 Feb 1;7(1):1.

22. Taha U, Ismail S, AbdAlla E, Abd Alilah K, Eltahir S, Mirghani S. Study on Reducing Maternal Mortality from Direct Obstetric Causes during 2013 in Sudan. Highlights on Medicine and Medical Science Vol. 18. 2021 Aug 14:78-87. DOI: https://doi.org/10.9734/bpi/hmms/v18/9491D.
23. World Health Organization. Trends in maternal mortality: 1990-2015: estimates from WHO, UNICEF, UNFPA, World Bank Group and the United Nations Population Division. World Health Organization; 2015. http://dx.doi.org/10.1016/ S0140-6736(15)00838

24. Tamale NR. Trends and Causes of Maternal Mortality at the Tamale Teaching Hospital in Ghana, between 2010 and 2016. International Journal of Applied Engineering Research. 2019;14(7):1703-8.

25. Akpan UB, Asibong U, Omoronyia E, Arogundade K, Agan T, Ekott M. Severe life-threatening pregnancy complications, "near miss" and maternal mortality in a tertiary hospital in southern Nigeria: a retrospective study. Obstetrics and Gynecology International. 2020 Jul 1;2020. DOI: https:// doi.org/ 10.1155/2020/3697637

26. Agha $\mathrm{S}$, Tappis $\mathrm{H}$. The timing of antenatal care initiation and the content of care in Sindh, Pakistan. BMC pregnancy and childbirth. 2016 Dec;16(1):1-9. DOI: https://doi.org/10.1186/ s12884-016-0979-8

27. Islam MM, Masud MS. Health care seeking behaviour during pregnancy, delivery and the postnatal period in Bangladesh: Assessing the compliance with WHO recommendations. Midwifery.2018Aug 1;63:8-16. DOI: https://doi.org/10. 1016/j.midw.2018.04.021 